Original Research Paper

\title{
Uncertainty Impact of the Effective Diffusion Coefficient on the Concrete Chemical Degradation
}

\author{
A. Badaoui \\ National School of Built and Ground Works Engineering, Sidi Garidi Kouba, Algiers, Algeria
}

Article history

Received: 25-01-2015

Revised: 31-03-2015

Accepted: 28-04-2015

\begin{abstract}
Reinforced concrete is the construction material widely used in civil engineering. However, knowledge of its long-term performance and the uncertain impact of the environment on his behaviour make it difficult to accurate assessment of the durability of structures with time. When a structure is put into service, it is likely to damage, which origin can be physical, mechanical or chemical. Chemical factors are frequently the most important, since the concrete can be degraded by reaction (dissolution, swelling) of the concrete constituents. In this paper, a probabilistic formulation is applied to carbonation phenomenon and statistics regarding carbonation time required for the carbonation depth reaches the reinforcement concrete are investigated by performing a parametric analysis which integrates the influence of variation of porosity and effective diffusion coefficient of carbonic gas.
\end{abstract}

Keywords: Chemical Factors, Carbonation Kinetics, Carbonation Time, Coefficient of Variation, Carbonic Gas $\mathrm{CO}_{2}$

\section{Introduction}

Carbon dioxide and chlorides are the most important buildings aggressive agents which may be exposed. They are responsible for one of the main mechanisms of degradation of existing structures.

These phenomena are respectively identified by the corrosion due to penetration of chlorides or corrosion by carbonation

The speed of concrete carbonation depends mainly on the dioxide carbon penetration inside the cement matrix. Indeed, the diffusion of carbon dioxide through the porous structure of concrete is determined by the Water to cement ratio and porosity. Badaoui et al. (2012; Castellote et al., 2001) and are identified in italic type, within parentheses.

\section{Concrete Carbonation Theory}

Carbonation originates from the low amount of carbon dioxide in the air; it reflects the action of $\mathrm{CO}_{2}$ diffusion within the pores of the concrete and reactions with hydrates. When the portlandite is consumed, the $\mathrm{pH}$ drops to a value below 9, thus initiating the corrosion of steels (Ang and Tang, 2005).

Carbonation has a beneficial aspect of cementitious materials; crystals of calcite $\mathrm{CaCO}_{3}$ that form from of the hydrates can increase the resistance of concrete to the diffusion of aggressive agents.

The $\mathrm{Ca}(\mathrm{OH})_{2}$ reacts with carbon dioxide to form calcite, according to the following reactions (Castellote et al., 2001) Equation 1-3:

$\mathrm{Ca}(\mathrm{OH})_{2} \rightarrow \mathrm{Ca}^{2+}+2 \mathrm{OH}^{-}$

$\mathrm{Ca}^{2+}+\mathrm{CO}_{3}^{2-} \rightarrow \mathrm{CaCO}_{3}$

$\mathrm{Ca}(\mathrm{OH})_{2}+\mathrm{CO}_{2} \rightarrow \mathrm{CaCO}_{3}+\mathrm{H}_{2} \mathrm{O}$

Portlandite carbonation is overall accompanied by water release of structure

\section{Statistical Investigation of Concrete Carbonation}

In this article, the statistics corresponding the time required for the carbonation depth reach the steel are studied, by performing a parametric study that incorporates the influence of the uncertainty of the effective diffusion coefficient of carbon dioxide and the porosity of the paste of the carbonated concrete on time carbonation, taking a log-normal distribution. 
To evolve towards the probabilistic approach, we used the Duracrete deterministic model calculating the carbonation time T1 according to following equation (Duracrete. 2000) Equation 4:

$T_{1}=\left[\frac{a d^{2}}{2 k_{e} k_{c} D_{e f f} C_{S} t_{0}^{2 \omega}}\right]^{\frac{1}{1-2 \omega}}$

$a$ is the quantity of material carbonated given by Equation 5:

$$
a=\frac{\beta_{c h} C H \alpha_{h} M_{C O 2}}{M_{c a o}}
$$

Where:

$M_{c o 2}$ and $M_{c a o}=$ The molar masses of carbonic gas and calcite

$\alpha_{h} \quad=$ The degree of hydration of cement

$\mathrm{CH}=$ The quantity of the Portland and $\beta_{\mathrm{ch}}$ translates the relation of the portland likely to react

$\mathrm{d}=$ The coating $\mathrm{d}=30 \mathrm{~mm}, \omega$ is the mesoclimatic factor $\omega=0.1$ Equation 6:

$k_{e}=\left(\frac{1-R H_{a b s}^{5}}{1-R H_{l a b}^{5}}\right)^{2.5}$

$$
\mathrm{RH}_{\mathrm{abs}}=75 \%, \mathrm{RH}_{\mathrm{lab}}=65 \%, \mathrm{k}_{\mathrm{e}}=0.69 \text {. }
$$

$k_{C}$ is a parameter taking account of the conditions of curing compound concrete, given by Equation 7:

$$
k_{c}=\left(\frac{t_{c}}{7}\right)^{-0.56}
$$

Where:

$t_{c}=$ The duration of cure, $t_{c}=1$ day and $k_{C}=3$

$D_{\text {eff }}=$ The effective coefficient of diffusion of $\mathrm{CO}_{2}$ Equation 8:

$D_{e f f}=1.6410^{-6} \varepsilon_{c}^{1.8}(1-R H)^{2.2}$

$\varepsilon_{c}$ is the porosity of the paste of the carbonated concrete

$\mathrm{Cs}$ is the $\mathrm{CO}_{2}$ pressure on the surface of the concrete, $\mathrm{Cs}=6.1 \mathrm{~kg} / \mathrm{m}^{3}$

$\mathrm{T}$ the expiry considers (year), $t_{0}$ is the reference period " 28 days"

\section{Study Materials}

The characteristics of studied concrete and cement chemical composition are shown in Table 1 and 2.
Table1. Portland cement chemical composition CEM I52.5R

\begin{tabular}{ll}
\hline Parameter & Value \\
\hline Cement & $365 \mathrm{Kg} / \mathrm{m}^{3}$ \\
Aggregates & $1850 \mathrm{Kg} / \mathrm{m}^{3}$ \\
Water & $182 \mathrm{Kg} / \mathrm{m}^{3}$ \\
Thermal cure (free cooling) & $6 \mathrm{Hà} 60^{\circ} \mathrm{C}$ \\
Cure time & 1 day \\
Water to cement ratio & 0.5 \\
\hline
\end{tabular}

Table 2. Concrete composition studied

\begin{tabular}{llll}
\hline $\mathrm{SiO}_{2}$ & $\mathrm{AL}_{2} \mathrm{O}_{3}$ & $\mathrm{Fe}_{2} \mathrm{O}_{3}$ & $\mathrm{CaO}$ \\
\hline $22 \%$ & $5.02 \%$ & $2.94 \%$ & $64.36 \%$ \\
$\mathrm{~K}_{2} \mathrm{O}$ & $\mathrm{Na}_{2} \mathrm{O}$ & $\mathrm{SO}_{3}$ & $\mathrm{MgO}$ \\
$0.47 \%$ & $0.26 \%$ & $1.94 \%$ & $2.07 \%$ \\
\hline
\end{tabular}

For the composition of concrete proposed, the effective coefficient of diffusion can be estimated at $D_{\text {eff }}=3.9210^{-12} \mathrm{~m}^{2} / \mathrm{s}$, with a value of porosity $\varepsilon_{c}=$ $0.45, \alpha_{h}=80 \%, \beta_{c h}=85 \%$ and $a=65.2 \mathrm{~kg} / \mathrm{m}^{3}$ (Badaoui et al., 2012).

It is considered that this concrete is located inside of a building where the humidity of the ambient air is medium or high. It is therefore subject to the exposure class $\mathrm{XC} 3$, the numerical values for the composition parameters are identical to those of the class XF1 (Norm NA 16002, 2004; Norm NA 442, 2006).

\section{Numerical Implementation of the Simulations}

One has to solve a conventional random problem for a large number of input parameters by using Monte Carlo simulations (Rubinstein and Kroese, 1981).

About 10000 independent samples of the parameters $D_{\text {eff }}$ and $\varepsilon_{c}$ with a log-normal distribution are generated and the deterministic numerical procedure is applied to each individual simulation, providing 10000 values of the time carbonation parameters. Finally, statistics of the depth and time factors (mean, standard deviation and confidence interval) are calculated.

The parameters of the lognormal distribution of $D_{\text {eff }}$ and $\mathrm{s}$ are expressed as follows Equation 9-12:

$$
\begin{aligned}
& \sigma_{\ln D e f f}^{2}=\ln \left(1+\frac{\sigma_{\text {Deff }}^{2}}{\mu_{D e f f}^{2}}\right) \\
& \mu_{\ln \text { Deff }}=\ln \left(\mu_{\text {Deff }}\right)-\frac{1}{2} \sigma_{\ln D \text { eff }}^{2} \\
& \sigma_{\ln \mathcal{E}_{c}}^{2}=\ln \left(1+\frac{\sigma_{\mathcal{E}_{c}}^{2}}{\mu_{\mathcal{E}_{c}}^{2}}\right) \\
& \mu_{\ln \mathcal{E}_{c}}=\ln \left(\mu_{\varepsilon_{c}}\right)-\frac{1}{2} \sigma_{\ln \mathcal{E}_{c}}^{2}
\end{aligned}
$$


where, $\left(\mu_{\text {Deff, }}, \sigma_{D e f f}^{2}\right)$ and $\left(\mu_{\varepsilon c}, \sigma_{\varepsilon c}^{2}\right)$ are statistics (mean and variance) of $D_{\text {eff }}$ and $\varepsilon_{\mathrm{c}}$ respectively.

The mean value of the effective coefficient of diffusion is $D_{\text {eff }}=3.9210^{-12} \mathrm{~m}^{2} / \mathrm{s}$ and the coefficient of variation $C v_{\text {Deff }}$ varies between 0 and 0.1 .

For the porosity $\varepsilon_{c}$, the mean value is $\mu_{\varepsilon c}=0.45$ and its coefficient of variation $C v_{\varepsilon c}$ also varies between 0 and 0.1 .

In order to determine the time carbonation, the ChiSquare goodness of fit test is used to evaluate the fit of the assumed carbonation parameters probability distribution and the shape of the corresponding histograms suggests a log-normal distribution, which is adopted in this study is shown in Fig. 1
The behavior of the coefficient of variation of carbonation time versus the number of realizations is also investigated and shown in Fig. 2.

The convergence of the final settlement coefficient of variation is observed for a number of realizations $\mathrm{N}_{\text {samp }}$ around 300 , this number is chosen equal to 10000 .

\section{Results and Discussion}

Figure 3 and 4 shows the statistics of carbonation time and the confidence interval depending on the variability of the effective coefficient of diffusion and the porosity.

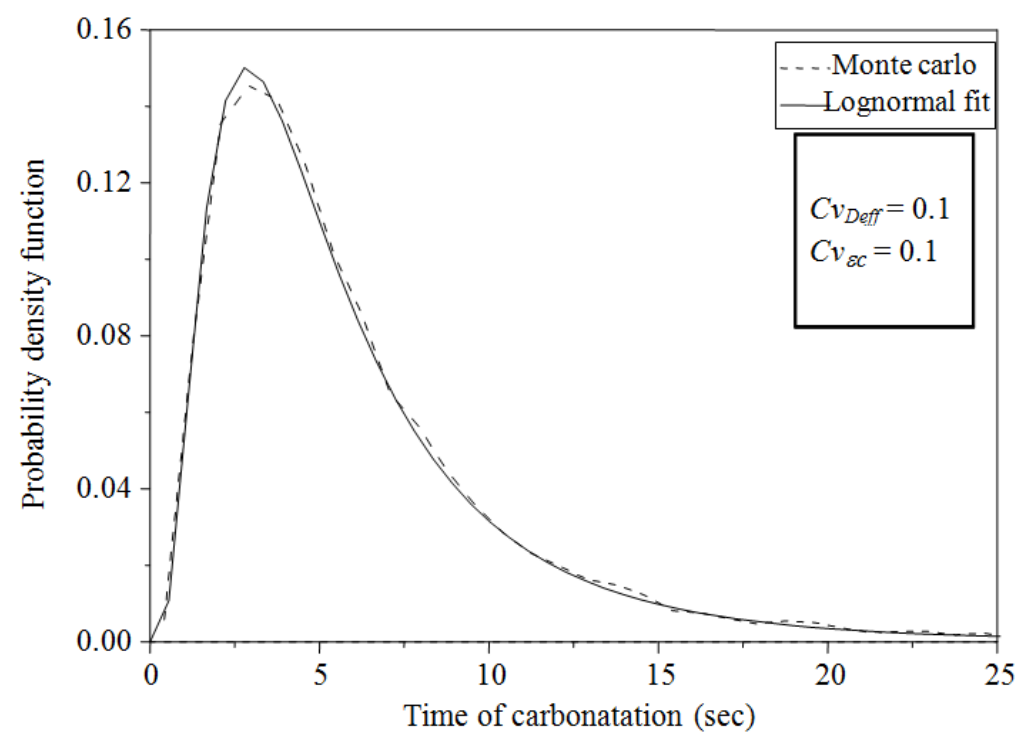

Fig. 1. Probability density function of the carbonation time versus $D_{\text {eff }}$ and $\varepsilon_{\mathrm{c}}$

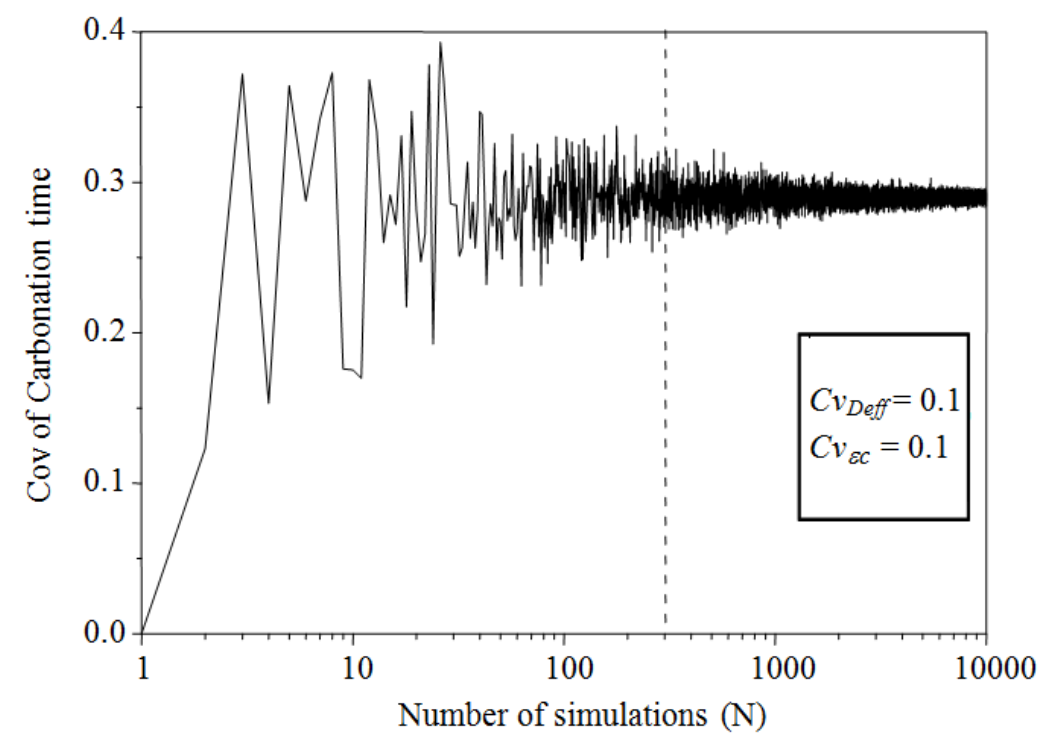

Fig. 2. Carbonation time coefficient of variation versus $D_{\text {eff }}$ and $\varepsilon \mathrm{c}$ 

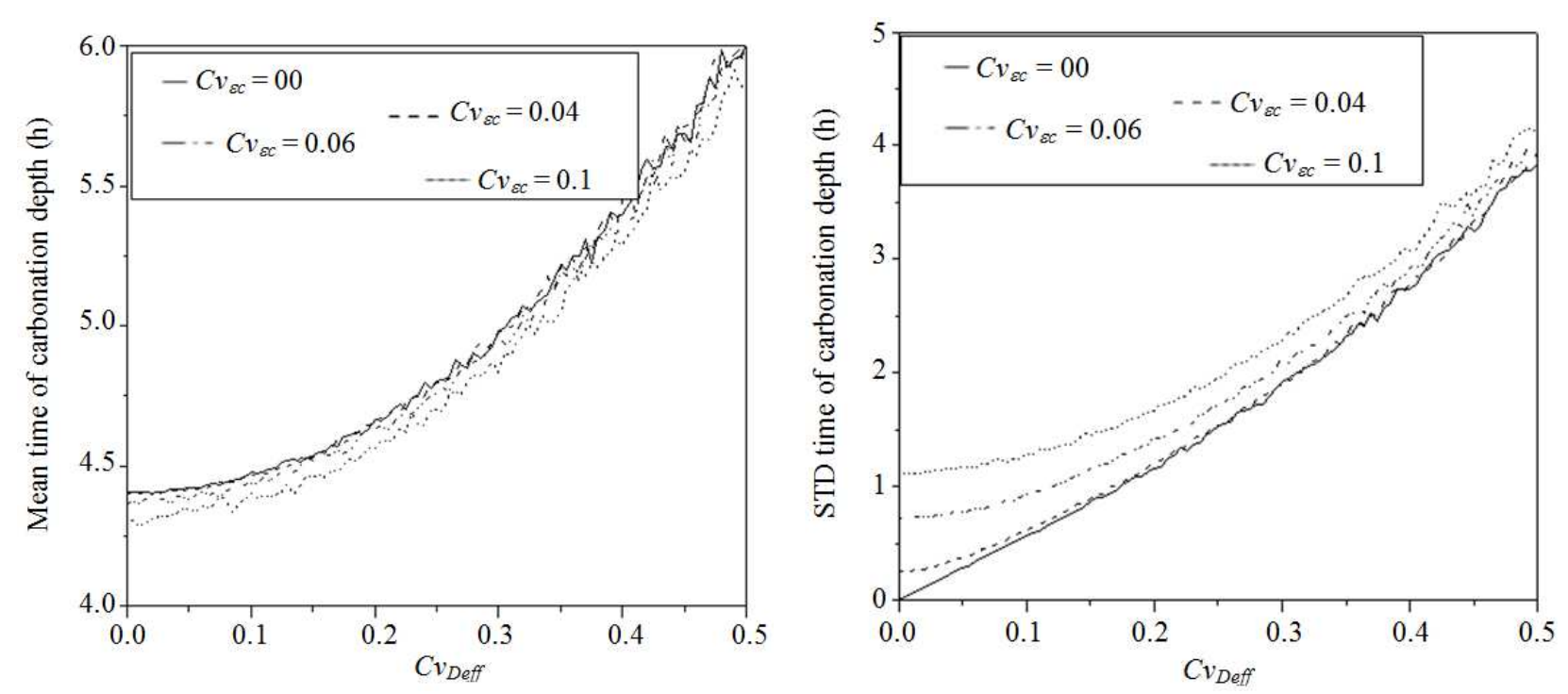

Fig. 3. Time of carbonation statistics versus $\mathrm{Cv}_{\text {Deff }}$ coefficient of variation
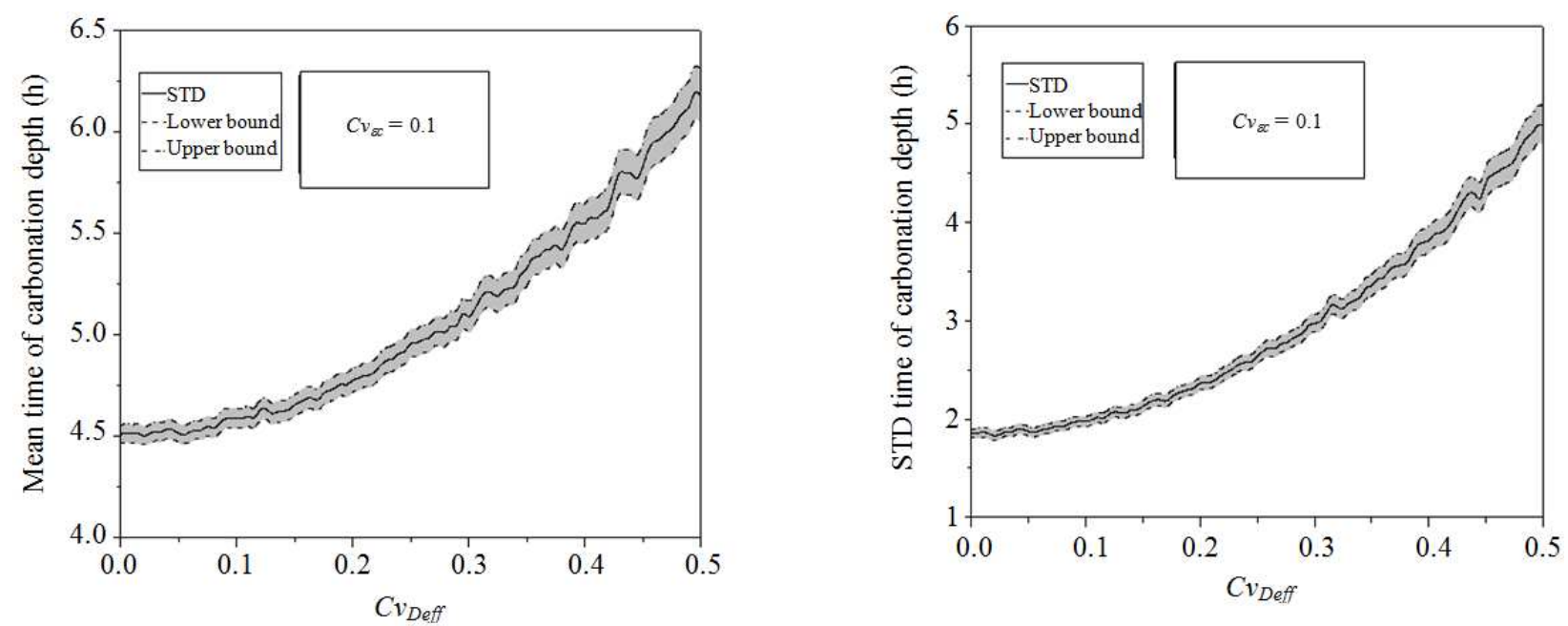

Fig. 4. Time of carbonation statistics and confidence intervals versus $\mathrm{Cv}_{\text {Deff }}$ coefficient of variation

We remark that when $C v_{D e f f}$ and $C v_{\varepsilon c}$ increase, the mean and the standard deviation augment significantly; indicating that the diffusion of $\mathrm{CO}_{2}$ from the outside to the heart of the concrete requires a longer time.

The confidence intervals are important indicating that the variability of the $D_{\text {eff }}$ affects the carbonation time.

The SDT value of the carbonation time increases which indicates that the uncertainty on the $\varepsilon c$ causes a delay in the carbonation process.

Reacting the hydrate of concrete with carbon dioxide leads to the production of water.

Greater the quantity of carbon dioxide released into the pores is larger, the amount of water formed during carbonation is important, this formation will also affect the process and increase the time of carbonation.

\section{Conclusion}

Carbonation of the concrete has an impact on the effective diffusion coefficient; this coefficient is decreased after carbonation. The interaction between the ions of carbon dioxide and the Calcium Silicate Hydrate surface (C-S-H) negatively charged form an electric double layer on the pores surface of the and slows the $\mathrm{CO}_{2}$ diffusion.

Indeed, the time required for the carbonation depth reaches the reinforcement concrete depends on the effective diffusion coefficient of $\mathrm{CO}_{2}$, " $D_{\text {eff }}$ ", which is 
linearly related to water to cement ratio and relative humidity.

\section{Acknowledgment}

The author gratefully acknowledges the reviewers for their commitment in reviewing the paper.

\section{Ethics}

This article is original and contains unpublished material. The corresponding author confirms that all of the other authors have read and approved the manuscript and no ethical issues involved.

\section{References}

Ang, A.H.S. and W.H. Tang, 2005. Probability Concepts in Engineering Planning and Design. 1st Edn., John Wiley and Sons.
Badaoui, A., M. Badaoui and F. Kharchi, 2012. Carbonic Gas Randomness Effect on Reinforced Concrete Carbonation. Engineering, 4: 6-10. DOI: $10.4236 /$ eng.2012.41002

Castellote, M., C. Alonso, C. Andrade, G.A. Chadbourn and C.L. Page, 2001. Oxygen and chloride diffusion in cement pastes as a validation of chloride diffusion coefficients obtained by steady-state migration tests. Cement Concrete Res., 31: 621-625. DOI: $10.1016 / \mathrm{S} 0008-8846(01) 00469-0$

Duracrete., 2000. Quantification statistique des variables à l'état limite. Contract BRPR-CT95-0132.

Norm NA 442, 2006. Cement-part composition, specifications and conformity criteria for common cements.

Norm NA 16002, 2004. Concrete: Specification, performance, production and conformity.

Rubinstein, R.Y. and D.P. Kroese, 1981. Simulations and Monte-Carlo Method, Wiley Series in Probability and Mathematical. 1st Edn., J. Wiley and Sons. 